\title{
Information Measures of Wages and Employment: Application to Senegal
}

\author{
Charles B. Moss ${ }^{1}$, Samba Mbaye ${ }^{2}$, James F. Oehmke ${ }^{3}$ \\ ${ }^{1}$ Food and Resource Economics Department, University of Florida, Gainesville, FL, USA \\ ${ }^{2}$ Department of Economics and Management Scienes, Universite Gaston Berger de Saint Louis, Saint Louis, \\ Senegal \\ ${ }^{3}$ United States Agency for International Development, Washington DC, USA \\ Email:cbmoss@ufl.edu
}

Received 5 November 2015; accepted 22 February 2016; published 25 February 2016

Copyright @ 2016 by authors and Scientific Research Publishing Inc.

This work is licensed under the Creative Commons Attribution International License (CC BY).

http://creativecommons.org/licenses/by/4.0/

(c) (i) Open Access

\begin{abstract}
This paper develops an information theoretic estimator of wage and employment shifts that provides quantification of and inference about type of employment (full time, part time, seasonal, unemployed) and industry share of employment. It is applied to determine the effects of two United States Agency for International Development (USAID) projects on employment in villages in the Tambacounda and Kedougou provinces in Senegal. The projects support the development of local forest-based production and processing industries. The results demonstrate statistically significant and positive effects on employment and the industry composition of employment.
\end{abstract}

\section{Keywords}

Information Theory, Agribusiness Development, Agro-Forestry, Forest Resources, Poverty Reduction

\section{Introduction}

An emerging literature recognizes the importance of rural non-farm employment in development processes [1]-[3] and poverty reduction [4]-[6], as do political statements such as the African Union's Malabo Declaration including support for creating "job opportunities for at least 30\%" of African youth, focused on rural and agribusiness employment. Yet the development literature is relatively under-invested in empirical measurement that quantifies a systemic shift from subsistence agriculture to rural wage employment. Current measures quantify changes in the share of employment in a particular sector such as manufacturing or services, but they do not provide systemic comparison of industry-level employment data across local rural economies. However, a de- 
velopment paradigm centered on rural economies transforming from subsistence agriculture to wage employment is best validated by analyzing the industry-level composition of employment within and across local rural economies.

This paper develops an information theoretic estimator of wage and employment shifts and associated inference. The estimator is applied to local rural economies in the Tambacounda and Kedougou regions of Senegal in order to analyze the effects of two USAID projects (collectively called WulaNafaa) on the structure of local employment. Specifically, the estimator provides information relevant to the research question: are WulaNafaa villages associated with a different industry employment structure than are comparison villages?

\section{The WulaNafaa Programs}

The study regions of Tambacounda and Kedougou are the largest in Senegal by area, the smallest in Senegal by population density, and the poorest in Senegal due in part to their rural nature. Yet these regions have productive agricultural land, rainfall sufficient to produce a variety of different crops, and the country's premier forest reserves. Forest products include charcoal, baobab fruit and fruit products, and lalo, a food emulsifier made from the bark of the baobab tree and preferred for improving the consistency of couscous and other foods. The development challenge is to unlock this agro-forest potential.

WulaNafaa is a Senegalese (Wolof) phrase meaning "benefits of the forest" and used as the name of two USAID projects implemented from 2000-2005 and 2006-2011, respectively. These projects helped implement Senegalese national legislation devolving control of natural resources to local populations by facilitating community-based management of local forests and establishing local processing industries associated with key forest resources. WulaNafaa focused on local development of baobab, charcoal, fonio and jujube production, processing and sales. It is hypothesized that as these local industries develop and offer more remunerative employment or entrepreneurial opportunities, that employment shares will shift away from traditional agriculture and into the forest-resource-based industries

\section{Methodology}

Figure 1 represents the labor allocation process in a local economy. The ordinates represent the marginal value product of labor. The abscissa is the quantity of labor; the length of the axis represents the fixed endowment of labor. For simplicity, consider the labor to be allocated across traditional agriculture, the charcoal industry, and the baobab industry. The quantity of charcoal labor increases from left to right starting at the left origin. The quantity of baobab labor increases from right to left starting at the right origin. The $M V P_{L C}$ and $M V P_{L B}$ curves represent the marginal value product of labor in charcoal and baobab industries, respectively; the horizontal line represents the marginal value product of labor in traditional agriculture. In the initial equilibrium the labor allocations are $L_{C}$ to charcoal, $L_{B}$ to Baobab, and $\bar{L}-L_{C}-L_{B}$ to agriculture.

WulaNafaa's primary effects are represented in upward shifts in the $M V P_{L C}$ curve to $M V P_{L C}^{\prime}$ and in the $M V P_{L B}$ curve to $M V L_{L B}^{\prime}$, which initially increase labor allocated to the charcoal and baobab industries. This causes a secondary effect of an upward shift in the marginal value product of labor in traditional agriculture because of reduced labor in agriculture, increased food expenditures from charcoal and/or baobab earnings, or investment in agricultural productivity enhancements from non-agricultural earnings. The new equilibrium labor allocations are $L_{C}^{\prime}<L_{C}, L_{B}^{\prime}>L_{B}$, and $\bar{L}-L_{C}^{\prime}-L_{B}^{\prime}<\bar{L}-L_{C}-L_{B}$ implying a decreased employment in traditional agriculture and charcoal and increased employment in baobab. The direction of the employment change in charcoal (or any single industry) depends on the slopes of the curves and the magnitudes of the shifts: it could be the case that employment increases in both baobab and charcoal industries. With a fixed labor endowment the shares of labor will move in the same direction as the quantity of labor, although generalizing to an upward sloping labor supply could in principle change this situation. This means that reliance on employment or employment share in any single industry as an indicator of systemic change is problematical and highlights the importance of a systemic measure of employment change across all major industries. Hence a more comprehensive measure is needed.

In information theory, $f$-divergence refers to a measure of the divergence between two probability distributions: since employment shares are non-negative and sum to one they act as probability distributions. Formally, let $Z_{1}, Z_{2}: \Re^{N} \rightarrow \Re^{+}$be probability density functions taking on non-negative values except possibly on a set of measure zero. An $f$-divergent information functional is defined by 


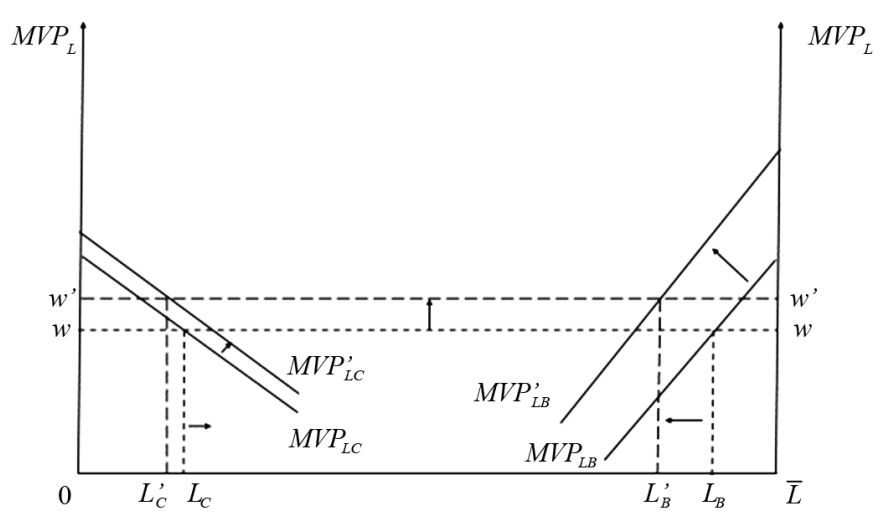

Figure 1. Labor market with WulaNafaa effects.

$$
I\left(Z_{1}, Z_{2}\right) \equiv \int_{\Re^{N}} Z_{1}(x) f\left(\frac{Z_{1}(x)}{Z_{2}(x)}\right) \mathrm{d} x
$$

where $f$ is a convex function with $f(1)=0$. Then $I\left(Z_{1}, Z_{2}\right)$ is non-negative and equal to zero if and only if $Z_{1}(x)=Z_{2}(x) \forall x^{1}$. Specification of $f(x)=-\ln (x)$ results in the Kullback-Liebler [8] divergence [9].

The current paper treats employment shares as probabilities and applies the Kullback-Liebler divergence to quantify the divergence between employment shares in the WulaNaffa villages $\mathrm{v}$. the comparison villages. The employment choices are represented by

$$
Z_{i j}=\left\{\begin{array}{l}
1 \text { if the individual } j \text { works in industry } i \\
0 \quad \text { otherwise }
\end{array}, i=1, \cdots, 9\right.
$$

where $i$ is the industry, $j$ is the individual. The industry $i$ employment share for group $g$ is:

$$
Z_{i g}=\frac{1}{N_{g}} \sum_{k \in g} Z_{k g}
$$

where $g \in\{1,2\}$ is a group (i.e., treatment [1] or control [2]), and $N_{g}$ is the number of individuals in group g, The Kullback-Liebler divergence (1) thus becomes

${ }^{1}$ To justify the conjecture that $I\left(Z_{1}, Z_{2}\right) \geq 0$ we build on Shannon and Weaver's original entropy model [7]. Both $Z_{1}$ and $Z_{2}$ are relative shares (i.e., numbers between zero and one). Thus, we let $Z_{1} \rightarrow p_{i}$ where $0 \leq p_{i} \leq 1$. First, we note that $p_{i} \ln \left(p_{i}\right) \leq 0$ with two boundaries- $\lim _{p_{i} \rightarrow 1} p_{i} \ln \left(p_{i}\right)=0$ and $\lim _{p_{i} \rightarrow 0} p_{i} \ln \left(p_{i}\right)=0$. Given these boundaries, the entropy measure defined by Shannon and Weaver is always positive

$$
J=-\sum_{i} p_{i} \ln \left(p_{i}\right) \geq 0
$$

Next, we define an alternative probability measure $Z_{2} \rightarrow q_{i}$ with an imperfect information measure

$$
\tilde{J}=-\sum_{i} p_{i} \ln \left(q_{i}\right) \geq 0
$$

given $0 \leq p_{i}, q_{i} \leq 1$. Following the results from the derivation of the entropy measure $\tilde{J}$ is minimized when $q_{i}=p_{i}$, or $J \leq \tilde{J}$ with equality when $q_{i}=p_{i}$. As a simple demonstration of this result consider the scenario where $i=1,2$. In this case,

$$
\begin{aligned}
& \tilde{J}=-p_{1} \ln \left(q_{1}\right)-\left(1-p_{1}\right) \ln \left(1-q_{1}\right) \Rightarrow \frac{\mathrm{d} \tilde{J}}{\mathrm{~d} q_{i}}=-\frac{p_{1}}{q_{1}}+\frac{1-p_{1}}{1-q_{1}}=0 . \\
& \Rightarrow \frac{p_{1}}{\left(1-p_{1}\right)}=\frac{q_{1}}{\left(1-q_{1}\right)}
\end{aligned}
$$

Finally, the conjecture that $I(p, q) \geq 0$ is demonstrated by the fact that

$$
I(p, q)=-J+\tilde{J}=\sum_{i} p_{i} \ln \left(p_{i}\right)-\sum_{i} p_{i} \ln \left(q_{i}\right) \geq 0 .
$$




$$
I\left(Z_{1}, Z_{2}\right)=\sum_{i=1}^{9} Z_{i 1} \ln \left(\frac{Z_{i 1}}{Z_{i 2}}\right)
$$

where $I\left(Z_{1}, Z_{2}\right) \rightarrow 0$ as $Z_{i 1} \rightarrow Z_{i 2} \forall i$.

Similar information estimators have been used in economics, e.g. Finke's [10] and Theil, Finke, and Flood's [11] re-estimations of Theil's [12] demand system. Further refinements applied to demand systems include Theil and Fiebig [13]; Thiel and Clements [14]; and Theil, Chung, and Seale [15]. In these cases, the objective was to select parameter estimates that minimized the information divergence between parameterized expenditure shares and observed shares. In the current context, the objective is to quantify and provide inference about the divergence between sets of observed employment shares in different regimes. In particular, we wish to know if development interventions have caused employment in the treatment group to diverge from employment in a comparison group representing traditional subsistence agriculture with limited forestry and non-agricultural opportunities. To the authors' knowledge, this represents the seminal application of information estimation to the question of employment change in developing economies.

The null hypothesis that there is no statistically significant difference between the employment shares is formalized in H0: $I\left(Z_{1}, Z_{2}\right)=0$. To test this hypothesis, bootstrap techniques are used to construct a distribution for $I\left(Z_{1}, Z_{2}\right)$ assuming $\mathrm{H} 0$ is correct. Hence, we start by drawing 15,000 draws of $2 / 3$ of the sample from the control group ( $\tilde{Z}_{i 2 k, j}$ is a draw $j=1, \cdots, \frac{2}{3} n$ observations from the original control sample group, $k=1, \cdots, 15000$ times for employment opportunities $i=1, \cdots, 9$ ) and calculating

$$
\bar{I}_{k}=\sum_{i=1}^{9} \bar{Z}_{i 2 k} \times \ln \left[\frac{\bar{Z}_{i 2 k}}{Z_{i 2}}\right] \text { such that } \bar{Z}_{i 2 k}=\frac{1}{\frac{2}{3} n} \sum_{j=1}^{\frac{2}{3} n} \tilde{Z}_{i 2 k, j} .
$$

where $\bar{Z}_{i 2 k}$ is the average of $\tilde{Z}_{i 2 k, j}$ for draw $k$. Repeating this random draw $2 n / 3$ times allows computation of a single observation $\mathrm{k}$ of the bootstrapped shares of employment, $\bar{Z}_{i 2 k}$ [right equality in Equation (5)]. Repeating the bootstrapping 15,000 times results in a set of employment shares that are then used to compute a measure of information based on the sample mean $\left(\bar{I}_{k}\right)$ in the left equality of Equation (5). Sorting the $\bar{I}_{k}$ in ascending order and assigning each a likelihood value of 1/15,000 we construct an empirical cumulative density function for the information measures which can be used for inference in much the same way we use the tabular values for the normal distribution.

\section{Data and Results}

USAID commissioned a survey of 20 households in each of 20 villages in Tambacounda and Kedougou that included questions on the employment status of each household member [16]. The sample contains 2109 individuals with 726 individuals in the control group (villages not targeted by WulaNafaa) and 1381 individuals in the WulaNafaa villages. Nine employment categories were defined: charcoal, baobab, lalo, jujube, fonio, livestock, other agriculture, students, and unemployed. While most individuals report primary employment in a single industry, several report more than one primary industry. In these cases, we divide employment equally across reported primary industries.

The primary employment shares are presented in Table 1. The primary employment shares in "other agriculture" are noticeably lower in the treatment group than in the control group, as is employment in charcoal or as a student. Treatment group employment shares in the Baobab and Lalo industries are larger than the comparison group shares. These share differences are consistent with a situation in which the treatment villages are more developed in terms of employment than are comparison villages. It remains to be seen if these shifts are statistically significant.

For the null hypothesis that employment shares are equal $I\left(Z_{1}, Z_{2}\right)=0.1423$, the bootstrapped $1 \%$ significance level is 0.01547, so that the null hypothesis is rejected at any standard significance level. Extending our framework slightly, we apply the information estimator $I\left(\zeta_{1}, \zeta_{2}\right)$ to the shares of type of employment (e.g., we aggregate the employment for each industry into part time, seasonal, full time, student, and unemployedsome individuals who work in the charcoal industry may be either part time, seasonal, or full time employees) 
(Table 2). This sample was slightly smaller than the original sample. It contained 1696 individuals. Of this total 632 individuals were from the control villages and 1,064 were from villages effected by WulaNafaa. Successful development would be associated with lower unemployment and more full time work. The evidence suggests that the number of full time employees increased by 1.2 percent (from 0.0697 to 0.0818 ). However, the results also depict a slight increase in the rate of unemployment from 0.0507 to 0.0845 across the groups. The results are somewhat complex. Overall the shares of people employed less than full time (i.e., part time plus seasonal) is similar for each group (i.e., 53.6 percent for the control group versus 53.3 percent for the treatment group). Comparing the sample in Table 1 with the sample in Table 2, the shares of unemployed for both groups and the share of students is slightly higher in the second sample. The difference stems from whether the individual answered the employed individuals answered the question on employment status. Employed individuals who did not answer this question were not included in the second sample while students and the unemployed were included. For the null hypothesis that employment shares by type are equal $I\left(\zeta_{1}, \zeta_{2}\right)=0.02199$. Given that the bootstrapped $1 \%$ significance level is 0.01394 , the null hypothesis of no development difference is rejected at any conventional level of significance.

\section{Conclusions and Implications}

Application of a novel information measure of employment patterns indicates that the treatment group-those villages participating in WulaNafaa-have a significantly different employment patterns than similar control villages in Senegal. Treatment villages have a full-time employment is higher than that in control villages and the employment shares in sustainable forest-resource based industries are significantly higher. However, baseline data are not available and so these findings are associational and not causal.

The method and results lead to three conclusions: first, the information measure of employment status and industry share divergence provides both economically and statistically relevant information on program success and/or development status. Second, the WulaNaffa villages are associated with a higher and statistically distinct

Table 1. Employment shares for control and treatment groups.

\begin{tabular}{ccr}
\hline & \multicolumn{2}{c}{ Employment Shares } \\
\cline { 2 - 3 } Industry & Control $\left(Z_{1}\right)$ & Treatment $\left(Z_{2}\right)$ \\
\hline Charcoal & 0.1593 & 0.0917 \\
Baobab & 0.1331 & 0.1935 \\
Lalo & 0.0342 & 0.1282 \\
Jujube & 0.0822 & 0.0758 \\
Fonio & 0.0450 & 0.0748 \\
Livestock & 0.0007 & 0.0042 \\
Other Agriculture & 0.2025 & 0.1352 \\
Student & 0.2989 & 0.2314 \\
Unemployed & 0.0441 & 0.0651 \\
\hline
\end{tabular}

Table 2. Employment status for control and treatment groups.

\begin{tabular}{ccc}
\hline Status & Control $\left(\zeta_{1}\right)$ & Treatment $\left(\zeta_{2}\right)$ \\
\hline Part Time & 0.3629 & 0.4051 \\
Seasonal & 0.1727 & 0.1278 \\
Full Time & 0.0697 & 0.0818 \\
Student & 0.3440 & 0.3008 \\
Unemployed & 0.0507 & 0.0845 \\
\hline
\end{tabular}

Sample size: 1696 individuals with 632 in the control villages and 1064 in the treatment villages. 
development status, at least with respect to employment; third, it is worthwhile. In both cases, the differences are consistent with the objectives of the program. The employment share in other agriculture is higher in the control villages while employment in baobab fruit, and Lalo industries are higher in the treatment villages. Hence, there is evidence that the programs increased employment in resource friendly industries and reduced employment in Charcoal production which is considered extractive. While our theory does not explicitly suggest changes in employment status, the results indicate that full time employment in the treatment villages increased ten-fold. However, unlike the results for the industrial composition of employment, this result is considered preliminary due to the presence of several missing values in the employment status of the WulaNafaa group. Additional work on potential estimators including the possibility of resampling from the observed group to impute the missing values is necessary to very these preliminary results.

\section{References}

[1] Lanjouw, J.O. and Lanjouw, P. (2001) The Rural Non-Farm Sector: Issues and Evidence from Developing Countries. Agricultural Economics, 26, 1-23. http://dx.doi.org/10.1111/j.1574-0862.2001.tb00051.x

[2] Haggblade, S., Hazell P. and Reardon T. (2010) The Rural Non-Farm Economy: Prospects for Growth and Poverty Reduction. World Development, 38, 1429-1441. http://dx.doi.org/10.1016/j.worlddev.2009.06.008

[3] Brooks, K, Xorya, S. and Gautam, A. (2013) Job’s for Africa’s Youth. 2012 Global Food Policy Report, International Food Policy Research Institute, Washington DC. http://dx.doi.org/10.2499/9780896295537

[4] De Janvry, A. and Sadoulet E. (2010) Agricultural Growth and Poverty Reduction: Additional Evidence. World Bank Research Observer, 25, 1-20. http://dx.doi.org/10.1093/wbro/lkp015

[5] Christiaesen, L and Todo, Y. (2014) Poverty Reduction during the Rural-Urban Transformation-The Role of the Missing Middle. World Development, 63, 43-58. http://dx.doi.org/10.1016/j.worlddev.2013.10.002

[6] World Bank (2013) The World Development Report 2013: Jobs. The World Bank, Washington DC. http://dx.doi.org/10.1596/978-0-8213-9575-2

[7] Shannon, C.E. and Weaver, W. (1963) The Mathematical Theory of Communication. University of Illinois Press, Chicago.

[8] Kullback, S. and Leibler, R.A. (1951) On Information and Sufficiency. Annals of Mathematical Statistics, 22, 79-86. http://dx.doi.org/10.1214/aoms/1177729694

[9] Liese, F. and Vajda, I. (2006) On Divergences and Informations in Statistics and Information Theory. IEEE Transactions on Information Theory, 52, 4394-4412. http://dx.doi.org/10.1109/TIT.2006.881731

[10] Finke, R. (1983) Goodness of Fit and Outliers in Cross-Country Demand Systems. Economics Letters, 13, 303-307. http://dx.doi.org/10.1016/0165-1765(83)90186-6

[11] Theil, H., Finke, R. and Flood, L.R. (1984) Minimum Information Estimation of Allocation Models. Economics Letters, 15, 251-256. http://dx.doi.org/10.1016/0165-1765(84)90109-5

[12] Theil, H. (1975) Theory and Measurement of Consumer Demand Volume 1. North-Holland, Elsevier, New York.

[13] Theil, H. and Fiebig, D.G. (1984) Exploiting Continuity: Maximum Entropy Estimation of Continuous Distributions. Ballinger, Cambridge.

[14] Theil, H. and Clements, K.W. (1987) Applied Demand Analysis: Results from System-Wide Approaches. Ballinger, Cambridge.

[15] Theil, H., Chung, C.-F. and Seale, Jr., J.L. (1987) International Evidence on Consumption Patterns. JAI Press, Greenwich.

[16] Mbaye, S. (2013) WulaNafaa Study Report. Mimeographed Paper, University of Gaston-Berger, St. Louis. 